\title{
HOW DOES TAKT PRODUCTION CONTRIBUTE TO TRADE FLOW IN CONSTRUCTION?
}

\author{
Pekka Kujansuu ${ }^{1}$, Joonas Lehtovaara ${ }^{2}$, Saara Salerto ${ }^{3}$, \\ Olli Seppänen ${ }^{4}$, and Antti Peltokorpi ${ }^{5}$
}

\begin{abstract}
Takt production has gained increased attention over the past decade inside the Lean Construction community. Several case studies have shown that implementing takt has positive effects on construction production, increasing flow by decreasing various types of waste. However, evidence on how takt production actually affects the flow of trades has been contradictory. The purpose of this study is to gain a better understanding of how implementing takt production, which heavily focuses on improving the flow of processes, affects the flow of trades.

This was conducted as a single case study. We collected and analyzed 650 hours of video material by observing one takt area over a period of six weeks, in addition to document observation and nine semi-structured interviews, including general contractor and trade partner personnel. We then classified and analyzed the results in light of propositions based on a literature review. Lastly, we drew our conclusions regarding what effects takt implementation has on trade flow.

The observations showed that even though the beginnings of the takt production resembled the traditional firefighting way of working, this more structured method stabilized production and positively impacted trade flow.
\end{abstract}

\section{KEYWORDS}

Flow, takt production, waste, trade flow

\section{INTRODUCTION}

Production flow can be perceived from the viewpoint of two intersecting perspectives: process and operations flow (Shingo and Dillon 1989). While the first refers to the flow of products in the production line, the latter refers to the flow of work at an individual workstation, looking at production from the perspective of worker efficiency. In order to address these flows in construction, the roles of locations should be considered. In

1 Development Engineer, Skanska Oy, Finland, pekka.kujansuu@,skanska.fi, orcid.org/0000-0002$\underline{5672-1101}$

2 Doctoral Candidate, Department of Civil Engineering, Aalto University, Finland, Joonas.lehtovaara@aalto.fi, orcid.org/0000-0002-4761-3811

3 Site Supervisor, Skanska Oy, Finland, saara.salerto@skanska.fi, orcid.org/0000-0001-8222-5470

4 Associate professor, Department of Civil Engineering, Aalto University, Finland, olli.seppanen@aalto.fi, orcid.org/0000-0002-2008-5924

5 Assistant Professor, Department of Civil Engineering, Aalto University, Finland, antti.peltokorpi@aalto.fi, orcid.org/0000-0002-7939-6612 
manufacturing, the product moves through production lines and processes, whereas in construction the processes and trades move through locations, with the product itself never moving (Sacks 2016). The Transformation-Flow-Value (TFV) theory of production (Koskela 2000) addresses these flows in construction as 'transformation' (trade flow, referring to the workers' ability to effectively work thorough the locations) and 'flow' (process flow, enabling the processes to effectively flow through a location) (Sacks 2016).

Location-based planning and control methods, such as LBMS, have focused on enabling the flow of trades, thus enabling continuous resourcing for the workers (e.g., Kenley and Seppänen 2010). However, takt production takes a different approach, aggressively focusing on the process flow by utilizing capacity buffers instead of traditionally preferred time and space buffers (Frandson et al. 2015). Even though takt enables better process flow by, for example, minimizing work-in-progress (WIP), it may simultaneously reduce workers' efficiency. Takt production has been reported as causing an unnecessary sense of urgency and stress for workers (Frandson et al. 2015), as well as unoptimized resource usage (Lehtovaara et al. 2019), with simulations showing an excess of waiting hours for the workers (Seppänen 2014). However, as recent case studies have also demonstrated increased transparency (Dlouhy et al. 2016) with better worker efficiency (Vatne and Drevland 2016; Binninger 2019), these findings appear to be contradictory.

There is thus a need to further study how takt production affects the flow of the trades. This study aims to contribute to the research gap by answering the following research question: How does implementing takt production impact trade flow? Our goal is pursued by first forming propositions based on the literature and then evaluating them in light of a case study.

\section{FORMULATION OF PROPOSITIONS}

Takt production enables a more organized working environment (Frandson et al. 2013), which can decrease the unnecessary movement of the trades. We therefore propose that P1: Takt production decreases unnecessary movement.

Takt production gives workers a transparent view of production. They thus understand where they should be working at a given time. This frees up time from fighting on site for workable space (Frandson et al. 2013; Frandson and Tommelein 2014; Faloughi et al. 2015). We propose that P2: Takt production decreases inefficient work. Takt production also increases the space utilization rate, decreasing the amount of time when location progress waits for the worker. The utilization of space is increased by synchronizing work tasks and preferring capacity buffers rather than time buffers (Frandson et al. 2013; Frandson et al. 2015). With that in mind, we posit that P3: Takt production might reduce waiting time.

Takt production is proposed to reduce overproduction (Frandson et al. 2013; Haghsheno et al. 2016). One type of overproduction occurs when work is done too early, and trades move to the next area earlier than scheduled; with takt production, the production can be planned to flow at a constant rate (Frandson et al. 2013). Thus, we propose that P4: Takt production decreases overproduction.

In takt production, control of production is often precise and fast-paced. Because of the minimized time and space buffers, the variation between production is noticed immediately after takt ends. This leads to identifying defects related to the production early on and makes it possible for workers to receive feedback sooner (Frandson et al. 
2013; Haghsheno et al. 2016; Dlouhy et al. 2017). This leads to our fifth proposition: P5: Takt production reduces defects.

Well-planned and controlled takt production decreases variability, and it thus increases the stability of the production (Haghsheno et al. 2016). The decline of variability in production decreases the waste of making-do. For example, the handover of a takt area from one trade to another provides an opportunity to verify if the previous work has been done as planned (Frandson et al. 2013). By keeping the takt areas available for one trade at a time, there is a chance for keeping the workable areas free and with minimal disturbance (Frandson et al. 2013; Tommelein 2017). If the workers know where they should be working at a given time, the amount of making-do can be decreased. Thus, we propose that P6: Takt production decreases making-do.

\section{RESEARCH METHOD}

A single case study was conducted to validate the formed propositions. The case project was a 40,000 square-meter, multi-story office building in Helsinki, Finland, operated as a management contract project. The data collection was conducted by site observation with continuous video camera documentation, observations of project documents, and semi-structured interviews. We collected 650 hours of video material by observing one takt area over a period of six weeks. The document observation focused on the records of planned and tracked work tasks. The interviews were held after the observation period and consisted of nine interviewees. The interviews were held with general contractor and trade partner representatives and concentrated on the use of takt production and how it affected trade work planning. The data was then analyzed and discussed in light of the proposals.

\section{RESULTS AND ANALYSIS}

The takt production plan for the interior phase was based on the six-step method by Frandson et al. (2013): 1) Gather information, 2) Define zones, 3) Understand the trade sequence, 4) Balance the workflow, 5) Understand the Individual Trade Duration, and 6) Production planning.

The takt production plan for the interior phase included drywall, plastering, painting, suspending ceilings, MEP, insulation, electrical work, and technical flooring. The focus of the takt planning was to make sure that those workers focused on tasks prior to technical flooring were able to complete their jobs in the specified areas. The takt production plan was implemented for a decrease of duration in the interior phase due to prolonged durations in previous phases and to stabilize the production to achieve a more predictable handover phase.

The takt plan commenced with a 5-day takt time, and three takt areas per block per floor were implemented. The case was the first takt production project for the general contractor and trade partners. The video camera documentation was conducted on the $\mathrm{C}$ block's $3^{\text {rd }}$ floor corridor takt area, which consisted of both corridors presented in Figure 1 . 


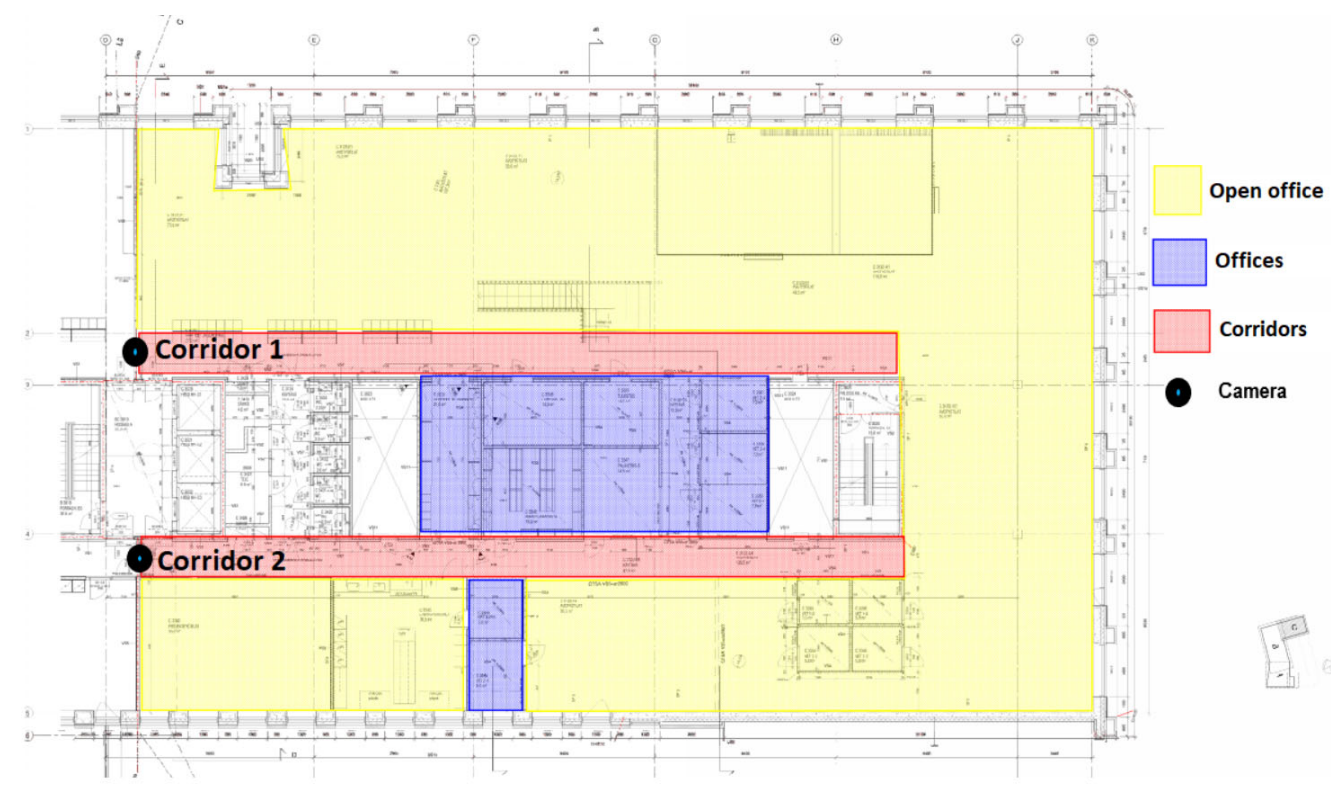

Figure 1: Three functional areas in a block in one floor

Propositions 1 and 2 stated that Takt production decreases unnecessary movement and that Takt production decreases inefficient work. In the early stage of the observation period, however, multiple interruptions between trades were noticed. Interruptions that affected the flow of trades were measured from the video recordings. Three types were observed, as listed in Table 1.

Table 1: Observed interruptions

\begin{tabular}{|c|c|}
\hline Interruption & Number of occasions \\
\hline Another trade in the way & 10 \\
Material in the way & 15 \\
Wrong trade sequence & 2 \\
\hline
\end{tabular}

These resulted in an increased amount of unnecessary movement between takt areas, as well as in an increased amount of inefficient work. However, the number of interruptions decreased in the later phase of the observation period, and further decreased when the production was stabilized after the initial problems, as seen in Table 2. Production documents tracking after the observation period and the results of the interviews themselves support these findings as well.

Table 2: Percentage of interruptions during the first 3 weeks of the observation period

\begin{tabular}{|c|c|}
\hline Interruption & $\begin{array}{c}\text { Percentage of interruptions } \\
\text { during the first 3 weeks }\end{array}$ \\
\hline Another trade in the way & $80 \%$ \\
Material in the way & $73 \%$ \\
Wrong trade sequence & $0 \%$ \\
\hline
\end{tabular}


After production stabilized, the amount of unnecessary movement and inefficient work radically decreased. Thus, propositions 1 and 2 are supported by the evidence.

Proposition 3 stated that Takt production might reduce waiting time. During the observation period, the interruptions affected the trade flow in such a way that the waiting time per trade was increased. There were multiple occasions where a trade was in the wrong area at the wrong time. This created waiting time for the other trades. The waiting time was also increased when multiple trades were working simultaneously in one takt area. The observed takt areas were long and narrow, which, especially at the beginning, led to a situation where trades continuously interfered with each other's work, as seen in Figure 2.

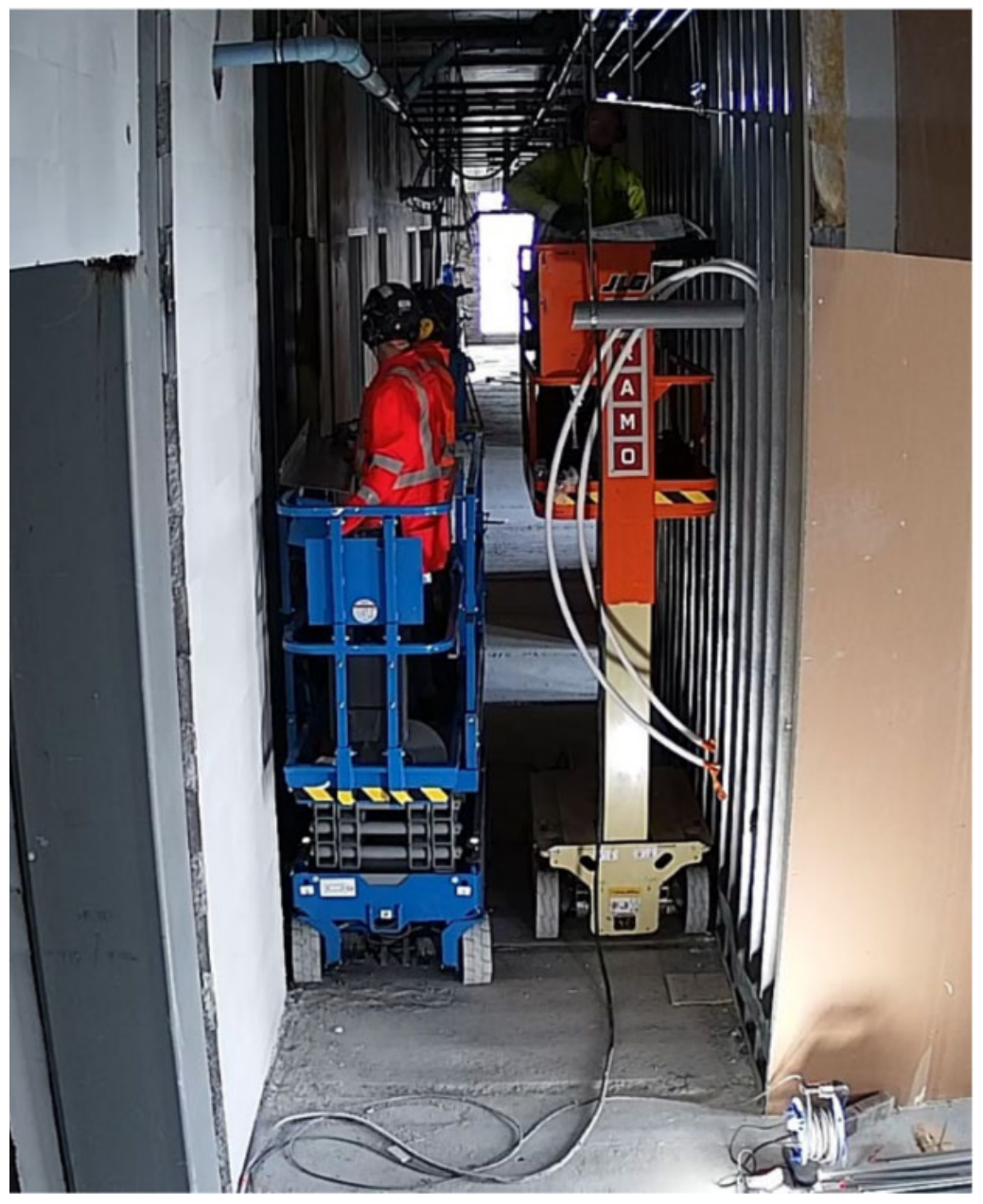

Figure 2: Two crews working side-by-side in the same takt area

As noticed in the later phase of the observation period, as well as from the production tracking documentation, the amount of waiting time for the trades seemed to decrease over time alongside the decrease in interruptions, as seen in Table 2. The interviewees stated that as the production stabilized, the amount of waiting time decreased in a way that they were able to start their work at a planned time, thus validating Proposition 3.

Proposition 4 stated that Takt production decreases overproduction. During the observation period, the amount of production planned to be done in the corridors evolved over time. In the early phase, the planned and completed work varied. During the 
observation period, certain trades were involved in overproduction. The observations and the tracked production planning documents showed that in the early phase of the observation period, a couple of trades were ahead of schedule, as seen in Figures 3, 4, and 5 .

During Week 14, the production had already started in the open office, where one trade had already finished work in advance. In the office blocks area, a trade started work four weeks in advance, as seen in Figure 3.

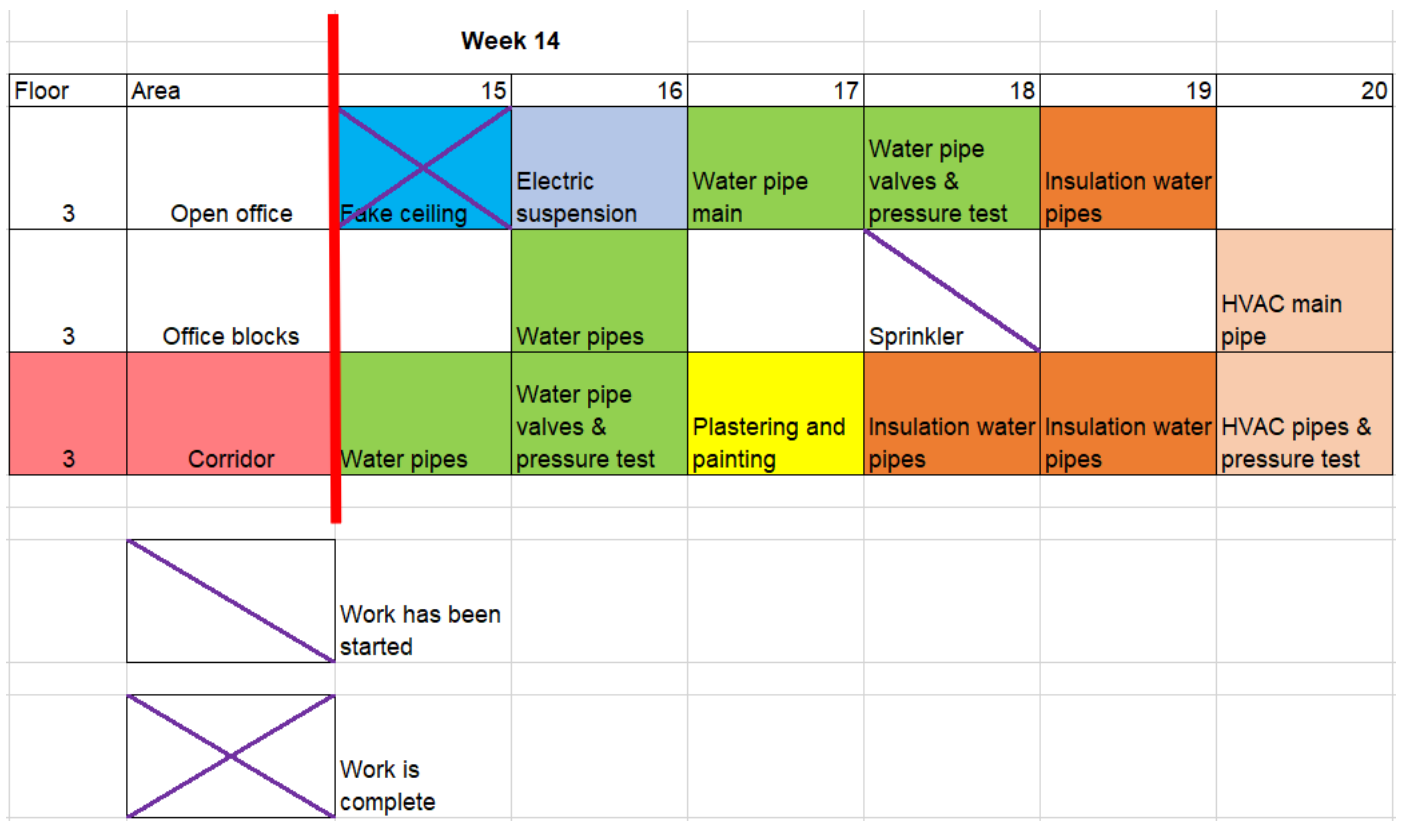

Figure 3: Week 14 of production

During Week 16, production went forward almost as planned. The observed corridor area was on schedule, while in the open office area one trade had started work a week early.

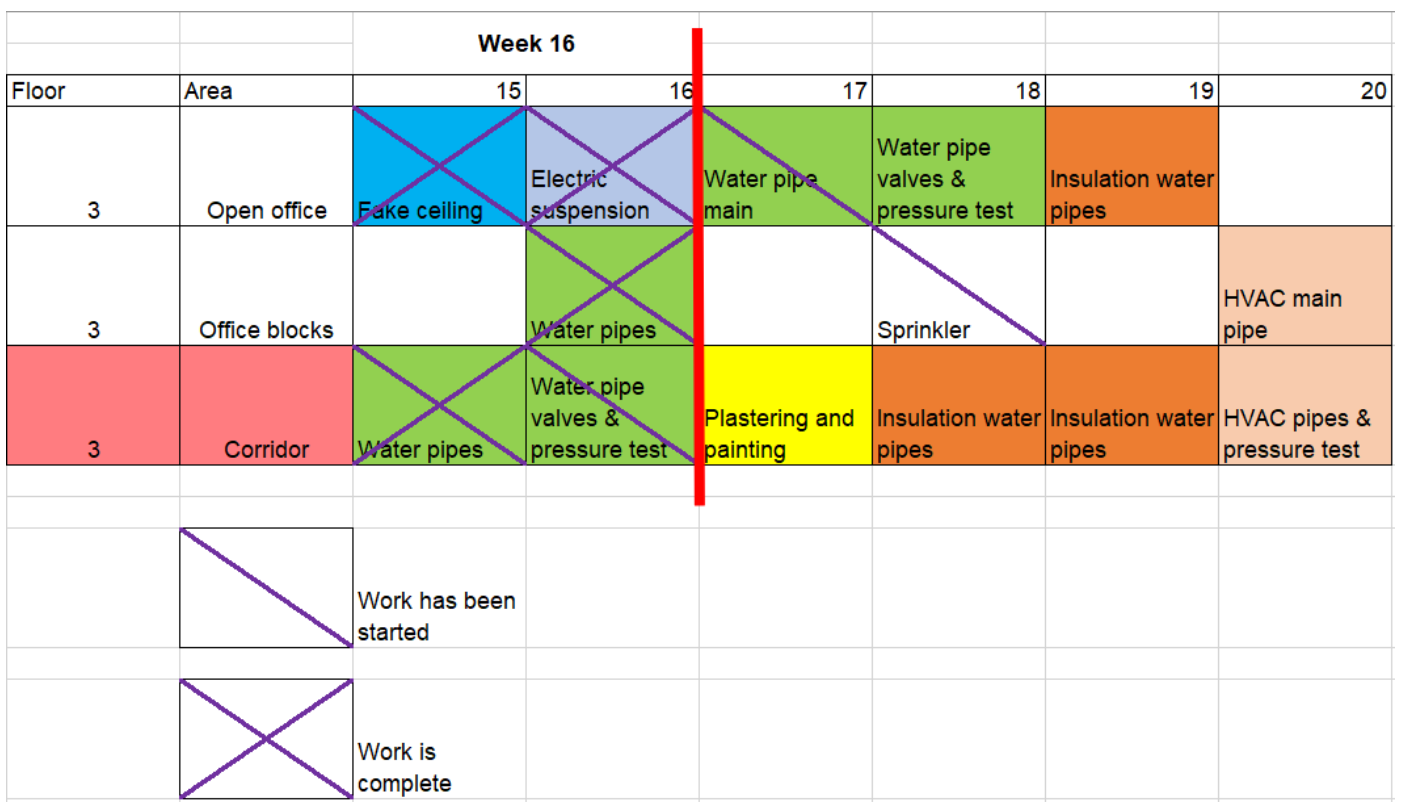

Figure 4: Week 16 of production 
During the last week of the observation period, when production became more stable, the number of early starts decreased. The results from the interviews indicate that as soon as the general contractor and the trades adjusted to this new way of working, the variety in production rates decreased. This can be seen in Figure 5, where production has stabilized and overproduction has been decreased. This supports our hypothesis from Proposition 4.

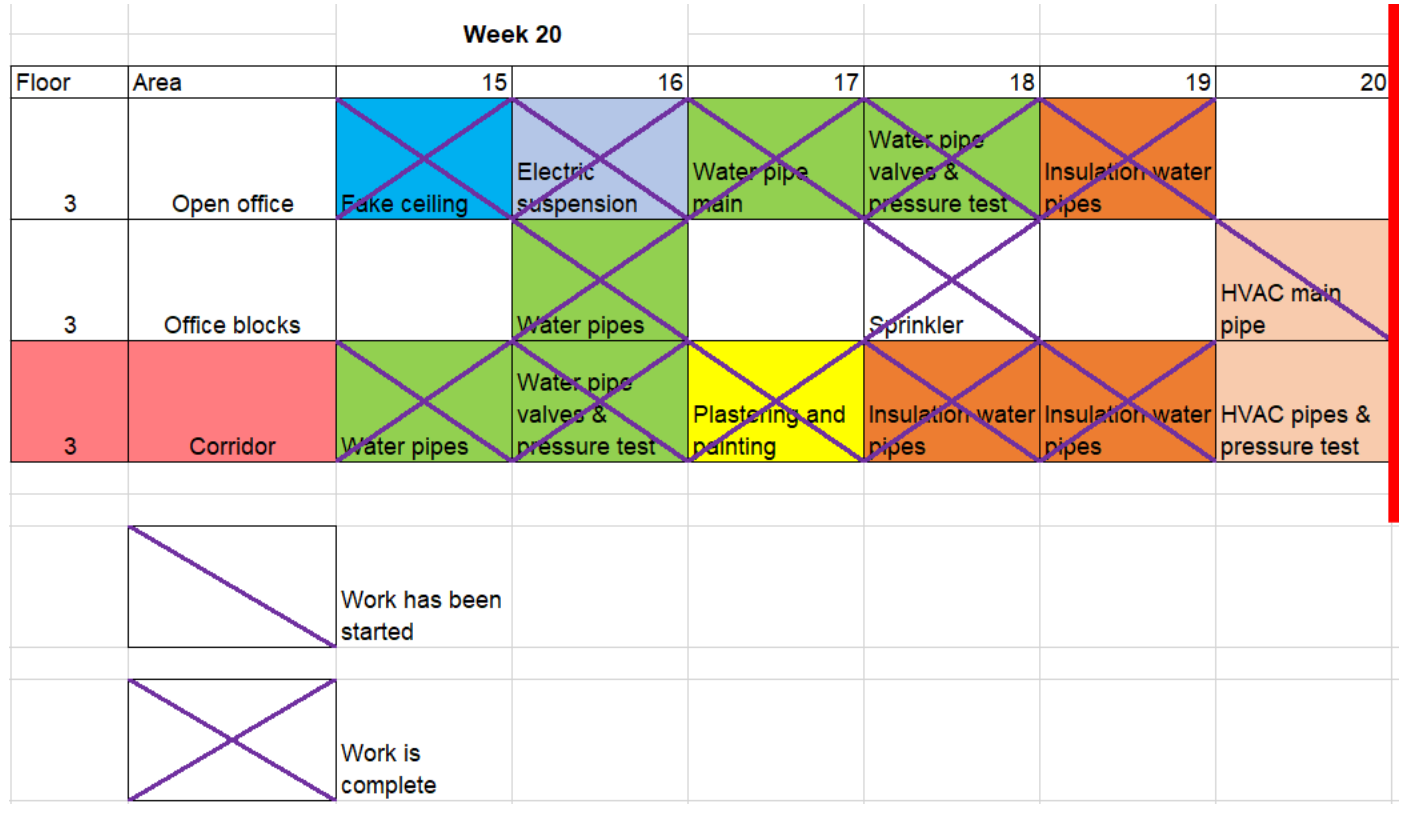

Figure 5: Week 20 of production

Proposition 5 stated that Takt production reduces defects. During the 650-hour observation period, not a single go back work was observed. Even though the production tracking documents showed that most of the planned work was eventually done, there was no indication that work was completed without defects. The interviews offered no definitive results on the decrease or increase of defects. One reason for this could be the limited time of observation. Thus, evidence for Proposition 5 was not found.

Proposition 6 stated that Takt production decreases making-do. During the early phase of the observation period, multiple interruptions were detected, as seen in Table 1 and Figure 2. The amount of overproduction behaved in a similar way, as seen in Figures 3, 4, and 5. After the general contractor and the trade partners became better adjusted to this way of working and had success in the production, the number of interruptions and general overproduction decreased. This also decreased the amount of making-do waste, and at the same time, increased the flow of trades. Proposition 6 was thus strongly supported.

\section{DISCUSSION}

The propositions based on the literature (Table 2) were evaluated during the analysis of the data. Four propositions ( $\mathrm{P} 1, \mathrm{P} 2, \mathrm{P} 3$, and $\mathrm{P} 4)$ were supported. One proposition (P5) was unable to be validated during the observation period. No defects or go-back work were documented, but due to the short observation period, we were unable to validate the proposition. One proposition (P6) was strongly supported. 
Table 2: Results of the propositions

\begin{tabular}{|c|c|}
\hline \multicolumn{1}{|c|}{ Propositions } & Results \\
\hline P1: Takt production decreases unnecessary \\
movement & Supports \\
P2: Takt production decreases inefficient work & Supports \\
P3: Takt production decreases waiting time & Supports \\
P4: Takt production decreases overproduction & Supports \\
P5: Takt production reduces defects & No support \\
P6: Takt production decreases making-do waste & Strongly \\
& supports \\
\hline
\end{tabular}

The support for propositions 1 through 3-the decrease of unnecessary movement, inefficient work, and waiting time with takt production-were apparent as soon as the production turned stable and the general contractor and trade partners were able to work in a more transparent way.

The support for Proposition 4 - the decrease of overproduction with takt productionwas noticed during multiple work phases when the planned work started weeks ahead of schedule. As soon as the general contractor and the trades became used to the new way of working, overproduction decreased. Support for Proposition 5 was never determined. During the recording period, no defects or go-back work were documented, and the observation of documents, as well as the interviews, did not give any feedback regarding this.

The possibility of decreasing the making-do waste with takt production was strongly supported by the observation results of spaces being overcrowded, as shown in Figure 2. This kind of behavior can thus be controlled with takt production, supporting proposition P6. It was noteworthy that during the six-week recording period, the surveillance takt areas were typically empty, and yet the takt work phases were able to be completed on time. This indicates that even though the takt production plan was seen by the general contractor and the trades as a tight plan with well-designed trade durations, there was a great deal of waste in the production plan itself.

\section{CONCLUSIONS AND FUTURE RESEARCH}

This study aimed to contribute to the research gap on how takt production affects the flow of trades. Based on the research gap, the following research question was formed: How does implementing takt production affect trade flow? The study was conducted as a single case study in a takt production project.

The data were based on 650 hours of video recordings of certain takt areas, documentation of tracked production, and multiple interviews of the general contractor's and trade partners' employees. Based on the data analysis, support was found for the positive effect on trade flow through the use of takt production. The positive effects on trade flow were based on the more structured way of production and the transparency between the general contractor and the trades. The flow of the trades increased as the production became more stable once trust between the stakeholders grew. Based on the findings, it seems that even though takt production fundamentally focuses on increasing the flow of processes, it also contributes positively to the flow of the trades. 
There are, however, many uncertainties regarding the single case and the amount of data gathered. There is a need for a more comprehensive study regarding the effects of takt production on trade flow. This study concentrated only on the flow of the trades inside a single takt production implementation case. Therefore, we see that a comparison between the trades flow on takt production and traditional construction projects would be beneficial. Also, the possibility of gathering more information and knowledge about the needs and restrictions regarding the flow of trades could be studied from the viewpoint of a portfolio flow of the trades (Sacks 2016).

\section{ACKNOWLEDGMENTS}

The research was supported by the Building 2030 consortium of Aalto University and 19 companies. www.building2030.com.

\section{REFERENCES}

Binninger, M., Dlouhy, J., Oprach, S. and Haghsheno S. 2016. Methods for Production Leveling-Transfer from Lean Production to Lean Construction. Proceedings of the 24th Annual Conference of the International Group for Lean Construction. Boston, MA, USA. 53-62.

Binninger, M., Dlouhy, J. and Haghsheno, S. 2019, 'Flow in Takted Projects-A Practical Analysis of Flow and Resource Efficiency' In:, Proc. 27th Annual Conference of the International Group for Lean Construction (IGLC). Dublin, Ireland, 3-5 Jul 2019. 1271-1282.

Bølviken, T., Aslesen, S. and Koskela, L. 2015. What is a good plan? Proceedings of the 23rd Annual Conference of the International Group for Lean Construction. Perth, Australia. Jul 29-31.93-102.

Dlouhy, J., Binninger, M., Oprach, S. and Haghsheno, S. 2016. Three-level Method of Takt Planning and Takt Control-A New Approach for Designing Production System in Construction. 24th Annual Conference of the International Group for Lean Construction. Boston, USA. 20-22 Jul 2016.

Dlouhy, J., Grobler, W., Binninger, M. and Haghsheno, S. 2017. Lean Equipment Installa-tion-Potentials of Using Takt Planning. Proceedings of the 25th Annual Conference of the International Group for Lean Construction. Heraklion, Greece. 721-728.

Faloughi, M., Linnik, M. and Murphy, D. 2015. WIP Design in a Construction Project Using Takt Time Planning. Proceedings of the 23rd Annual Conference of the International Group for Lean Construction. Perth, Australia. 163-172.

Frandson, A., Berghede, K. and Tommelein, I. D. 2013. Takt Time Planning for Construction of Exterior Cladding. Proceedings of the 21st Annual Conference of the International Group for Lean Construction. Fortaleza, Brazil. 31-2 Aug 2013. 527536.

Frandson, A.G., Seppänen, O., and Tommelein, I.D. 2015. Comparison between locationbased management and Takt Time Planning. Proceedings of the 23rd Annual Conference of the International Group for Lean Construction. Perth, Australia. 28$31 \mathrm{Jul} 2015.3-12$.

Frandson, A. and Tommelein, I.D. 2014. Development of a Takt-time Plan: A Case Study. Construction Research Congress 2014. Atlanta, Georgia. 19-21 May 214. 16461655. 
Haghsheno, S., Binninger, M., Dlouhy, J. and Sterlike, S. 2016. History and Theoretical Foundations of Takt Planning and Takt Control. Proceedings of the 24th Annual Conference of the International Group for Lean Construction. Boston, MA, USA. Part $1,53-62$.

Kenley, R., and Seppänen, O. 2010. Location-based management for construction: Planning, scheduling, and control. London New York: Spon.

Koskela, L. 2000. An exploration towards a production theory and its application to construction. VTT Publications 408. VTT Technical Research Centre of Finland, Espoo

Lehtovaara, J., Mustonen, I., Peuronen, P., Seppänen, O. and Peltokorpi, A. 2019. Implementing Takt Planning and Takt Control into Residential Construction. Proceedings of the 27th Annual Conference of the International Group for Lean Construction. Dublin, Ireland. 3-5 Jul 2019. 417-428.

Linnik, M., Berghede, K. and Ballard, G. 2013. An Experiment in Takt Time Planning Applied to Non-Repetitive Work. 21st Annual Conference of the International Group for Lean Construction. Fortaleza, Brazil. 31-2 Aug 2013. 609-618.

Sacks, R. 2016. What constitutes good production flow in construction? Construction Management and Economics. Vol. 34:9. 641-656.

Seppänen, O. 2014. A Comparison of Takt Time and LBMS Planning Methods. 22nd Annual Conference of the International Group of Lean Construction, Oslo, Norway.

Shingo, S., and Dillon, A.P. 1989. A study of the Toyota production system: from an industrial engineering viewpoint. Taylor and Francis, New York, NY. 304.

Tommelein, I. D. 2017. Collaborative Takt Time Planning of Non-Repetitive Work. $25^{\text {th }}$ Annual Conference of the International Group for Lean Construction. Heraklion, Greece. 9-12 Jul 2017. 745-752.

Vatne, M. E. and Drevland, F. 2016. Practical Benefits of Using Takt Time Planning: A Case Study. Proceedings of the 24th Annual Conference of the International Group for Lean Construction. Boston, MA, USA. 173-182. 